\title{
Religiosity as a Predictor of Emotional Stability among Adolescence
}

\author{
Nancy Agrawal ${ }^{1}, \operatorname{Kehksha}^{2}$
}

\section{ABSTRACT}

The study aimed at examining religiosity as a predictor of emotional stability among adolescence. The study was made by using random sampling method through the selection of 90 adolescents from Madrasa. The sample age ranged between 13 -18 years. Two instruments were used, named: Religiosity Scale and Emotional stability test. Data analysis involved the use of Pearson Product Moment correlation. The result showed positive correlation between religiosity and emotional stability. It appears from the trend of the result that religiosity and emotional stability are interrelated. It means if emotional stability increases the religiosity will also increases and vice versa. Though the relationship between these two variables is not very high but positive relationship exist between these two variables.

Keywords: Religiosity, Emotional stability, Adolescents

Adolescence is a period of personal and religious identity formation. Between the ages of 13 and 18, teenagers begin to more explicitly articulate their sense of who they are, including how they relate to their parents and their peers (Csikszentmihalyi \& Larson, 1984; Erikson, 1958).Adolescence means to grow that refers to one's transitional stage of physical and mental human development that occurs between childhood adulthood. This transition involves biological, social and psychological changes, though the biological and psychological ones are the easiest to measure objectively. It is that opportunity time in an individual's life when he or she learns to make choices based on experience, skills and values gathered in this period. Many kids announce the onset of adolescence with a dramatic change in behaviour. Adolescence is also the time when a fast paced family, lifestyle, and school, peer-pressure, conflicting emotions including a sense of isolation, a need to experiment push an adolescent to drugs, alcohol and unsafe behaviour. Parents, schools and the community at large share the responsibility of harnessing an adolescent's potential for the betterment of self and the society. Bullying is a huge problem that exists among adolescents, though it is neglected in this part of the world.

$1 \& 2$ Department of Pychology, Aligarh Muslim University, Aligarh

(C) 2015 I N Agrawal, Kehksh; licensee IJIP. This is an Open Access Research distributed under the terms of the Creative Commons Attribution License (http://creativecommons.org/licenses/by/2.0), which permits unrestricted use, distribution, and reproduction in any Medium, provided the original work is properly cited. 


\section{Role of Religiosity and Emotional Stability among Adolescence}

Bullying is the act of emotionally causing harm to others through verbal harassment, physical assault, or other more subtle methods of coercion such as manipulation. An adolescent can feel excitement gush through the views during this period of rapid growth. A sense of independence and risk taking behaviour takes place during this period. There are also several physical changes in the body because of the interplay of various hormonal changes. An adolescent is in the process of maturity with experience while interacting with others Adolescents can shift moods rapidly/vacillating between happiness and distress and self-confidence and worry. Conflicts with friends, school pressure and their life are full of fantasies, can exacerbate the labile Emotional state of adolescents. The complete lack of empathy in adolescents could mean, a more significant underlying mental health issue exists.

\section{SIGNIFICANCE OF THE STUDY}

As we know that adolescence is the critical stage of an individual's life, they are hardly satisfied with their lives and are more concerned about their career. They have to struggle a lot to reach their goals of achievement that lead them to get success in their lives. They have diverse attraction towards many things. Therefore their life is often under conflict. As teens are burdened with the choices of right or wrong, good or bad, yes or no. we must believe that their basis for decision-making comes from somewhere, whether it is societal standards, parental guidance or spiritual upbringing, the teen will do what is right for them in any situation. Taking the matter into consideration, I decided to conduct a study on this topic for which the participants are particularly adolescents. The aim of the present study is to examine; if adolescents are not satisfied with their lives, less devoted to their religions, and are emotionally immature; How far these factors predict emotional stability of adolescents. After all, adolescents are considered to be the building blocks of the nation.

\section{RELIGIOSITY}

Religion, sometimes used interchangeably with faith, is commonly defined as belief concerning the supernatural, sacred, or divine, and the practices and institutions associated with such belief. In its broadest sense some have defined it as the sum total of answers given to explain humankind's relationship with the universe. Religion takes an almost infinite number of forms in various cultures and individuals, but is dominated by a number of Major World Religions.

Occasionally, the word - Religion\| is used to designate what should be more properly described as a -Religious Organisation\|- that is, an organisation of people that supports the exercise of some religion, often taking the form of a-Legal entity.

Religiosity, in its broadest sense, is a comprehensive Sociological term used to refer to the numerous aspects of religious activity, dedication, and belief. Another term that would work equally well, though less used, is religiousness. In its narrowest sense, religiosity deals with how religious a person is, and less with how a person is religious. Donahue (1985) focused his review and meta-analysis on Gordon Allport's (1950) conceptualization of intrinsic religion as an end in 


\section{Role of Religiosity and Emotional Stability among Adolescence}

itself) versus extrinsic (religion as a means to an end, such as social interaction) religious orientation. The review and meta-analysis demonstrated a number of findings, including a positive mean correlation between extrinsic orientation and two negative characteristics ("prejudice" and "fear of death"), and a lack of a relationship between intrinsic orientation and these same characteristics.

\section{Dimensions of Religiosity}

Religiosity is a multidimensional phenomenon that has been conceptualized and measured in multiple ways (cf. John E. Fetzer Institute, 1999). Some of the dimensions of Religiosity are as under:

Organizational religiosity- it refers to participation in formal religious activities requiring some level of social interaction with other persons.

Religious Affiliation- It refers to identification with a particular religious group (e.g., Protestant, Catholic, Jewish, Muslim, Buddhist, no affiliation) or denomination.

Subjective Religiosity-It refers to an internal evaluation or self-ranking of individual religiousness.

Religious belief- It is a cognitive dimension of religiosity.

Non-organizational Religiosity- It refers to religious activities and practices that can be performed in solitude and do not require interaction with other persons.

Religious Coping- It refers to religious behaviours and activities that people engage in to cope with stress or difficult life situations. Examples of religious coping include praying to God for assistance or emotional support, reading scriptures for comfort, and discussing problems with ministers or chaplains.

\section{Emotional stability}

Emotions are defined as an acutely disturbed affective process or state which originates in the psychological situation and which is revealed by marked bodily changes in smooth muscles, glands and gross behaviour. Emotional stability is considered as one of the important aspect of human life. It is one of the effective determinants of the personality patterns. An emotionally stable individual has the capacity to withstand delay in satisfaction of needs, capability to tolerate a reasonable amount of frustration, belief in long term planning and is able of delaying or revising his expectations in terms of demands of the situations.

According to Smitson (1974) emotional stability is the process in which the personality is continuously striving for greater sense of emotional health, both intra-physically and intrapersonally. It has been emphasized that the emotionally stable individual has the capacity to withstand delay in satisfaction of needs, ability to tolerate a reasonable amount of frustration, belief in long term planning and is capable of delaying or revising his expectations in terms of demands of the situations. An emotionally stable child has a capacity to make effective adjustments with himself, members of the family, and his peers in the school, society and culture. However, stability does not mean merely the capacity for such attitudes and functions, but also the ability to enjoy them fully. 


\section{Role of Religiosity and Emotional Stability among Adolescence}

Sumal et al., (1998) examined the relationship between emotional stability and morality. It was observed that emotional stability was positively and significantly related to morality. Subjects who were emotionally stable obtained higher scores on morality compared to those who were emotionally unstable. It was concluded that morality depend on emotional stability.

Pajević I, Hasanović M, Delić A. to determine the influence of religious moral beliefs on the stability of adolescents' mental health. The sample consists of 240 mentally and physically healthy male and female adolescents attending a high school, who are divided into groups equalized by gender (male and female), age (younger 15, older 18 years); school achievement (very good, average student); behaviour (excellent, average); family structure (complete family with satisfactory family relations), and level of exposure to psycho-social stress (they were not exposed to specific traumatizing events). Subjects were assessed with regard to the level of belief in some basic ethical principles that arise from religious moral values. The score of the moral belief index was negatively correlated to neuroticism and depressiveness (Pearson's r=-0.242, $\mathrm{P}<0.001 ; \mathrm{r}=-0.311, \mathrm{P}<0.001$, respectively). Spontaneous and reactive aggressiveness and irritability were negatively correlated with the score of moral belief index (Pearson's $r=-0.197$, $\mathrm{P}=0.002 ; \mathrm{r}=-0.147, \mathrm{P}=0.023 ; \mathrm{r}=-0.350, \mathrm{P}<0.001$, respectively). Emotional instability is negatively associated with the moral belief index of the investigated adolescents (Pearson's $\mathrm{r}=-$ $0.324, \mathrm{P}<0.001)$. The moral belief index was highly negatively correlated with repression $(\mathrm{r}=-$ $0.206, \mathrm{P}=0.001)$, regression $(\mathrm{r}=-0.325, \mathrm{P}<0.001)$, compensation $(\mathrm{r}=-0.186, \mathrm{P}=0.004)$, transfer $(\mathrm{r}=-0.290, \mathrm{P}<0.001)$ and defensive orientation $(\mathrm{r}=-0.129, \mathrm{P}=0.046)$. Verified intellectualisation and reactive formation are in positive correlation with the moral belief index among our investigated adolescents (Pearson's $\mathrm{r}=0.168, \mathrm{P}=0.009 ; \mathrm{r}=0.356 ; \mathrm{P}<0.001$, respectively).A higher index of religious moral beliefs in adolescents enables better control of impulses, providing better mental health stability. It enables neurotic conflicts typical for adolescence to be more easily overcome. It also causes healthier reactions to external stimuli. A higher index of religious moral beliefs of young people provides a healthier and more efficient mechanism of anger control and aggression control. It enables transformation of that psychical energy into neutral energy which supports the growth and development of personality, which is expressed through socially acceptable behaviour. In this way, it helps growth, development and socialization of the personality, leading to the improvement in mental health.

\section{OBJECTIVES OF THE STUDY}

The purpose of the study is to measure the correlation between religiosity and emotional stability among the adolescence boys.

\section{Research question}

There are following research question in the present study

1. Is there any relationship between religiosity and emotional stability?

2. Is the correlation between religiosity and emotional stability is positive? 


\section{METHODOLOGY}

\section{Participants}

For the current research, the sample size consists of 50 students from madarsa, were selected by means of random sampling technique. The age ranged between 12 to 18 years.

\section{Research Tool}

Religiosity scale- Religiosity scale, developed by Dacker and Broota (1985) was used to assess the dependency of individuals on supernatural powers and faith upon someone. This scale contains 44 items in which 25 items were positively framed and 19 were negatively framed. The highest score of this scale is 220 and the lowest score is 44 . The reliability coefficient of this scale is 0.96 . Validity has been found satisfactory for this scale.

Emotional stability Test scale - This scale is introduced by Gupta and Singh (1985). It contains 15 items. The maximum score of this scale is 15 . This scale contains two positive and 13 negative items. Except 9 and 10, all the 'yes' responses are considered as negative. Negative responses are given +1 and 0 is given to all other items. The test-retest reliability and split half reliability of this scale are $0.55 ., .070$ respectively.

\section{Procedure}

The students were approached through management for the purpose of collecting information from students of madarsa. The data was collected individually. All the two scales were given to them and told about the purpose of the study and instructed to fill up the questionnaires as per the guide line printed in each questionnaire. They were asked to co operate to do this work for academic purpose and they agreed to give information on the entire questionnaire. In this way the data was collected and scored for the data analysis.

\section{DATA ANALYSIS}

Table - Pearson product moment co-efficient of correlation between religiosity and emotional stability among adolescence

\begin{tabular}{|l|l|l|l|l|l|}
\hline Sample & Variable & N & Df & r & result \\
\cline { 1 - 5 } Boys & Religiosity & 90 & 88 & 0.194 & significant \\
\cline { 2 - 3 } & Emotional stability & & & & \\
\hline
\end{tabular}

Significant at 0.5 level

For taking out the correlation between religiosity and emotional stability among adolescence, the obtained data were analyzed with the help of Pearson Product moment coefficient of correlation. The above table showed that $r$ value as found between religiosity and emotional stability is 0.194 . This value represents slightly positive correlation between both the variables. This value has been found significant at 0.5 level. It means that as the level of 


\section{Role of Religiosity and Emotional Stability among Adolescence}

religiosity increases, emotional stability will also increase among adolescence boys. Less religiosity develops less emotional stability among them. Though there is slight correlation, it has been stated that there is significantly positive relation between religiosity and emotional stability.

\section{IMPLICATIONS}

Motivating adolescence for prayers/ yoga sessions, designing multi faith prayer spaces, will strengthen adolescence's mental alertness, reduction of stress level and build up community spirit. For giving knowledge religion that is beneficial for increasing emotional stability \& hypothetical thinking. Furthermore, it is important to focus on the age period of adolescence because it has been characterized as unique, being fraught with up heals of emotion and battles with those in .It is important to acknowledge adolescence as religious beings.

\section{According to me}

We are not human beings having a spiritual experience; we are spiritual beings having a human experience.

\section{REFERENCES}

Allport, G. W. 1950. The individual and his religion: A psychological interpretation. New York: Macmillian.

Csikszentmihalyi, M., \& Larson, R. (1984). Being adolescent: Conflict and growth in the teenage years. New York: Basic Books.

Donahue, M. J. 1985. Intrinsic and extrinsic religiousness: Review and meta-analysis. Journal of Personality and Social Psychology 48:400-19.

Erikson, E. H. (1958). Young man Luther: A study in psychoanalysis and history. New York: Norton.

Pajević I, Hasanović M, Delić A. The influence of religious moral beliefs on adolescents' mental stability. Psychiatr Danub. 2007 Sep;19(3):173-83.

Smitson, W.S. (1974). The meaning of emotional maturity. MH, Winter 58, 9-11.

Sumal et al., (1998). Emotional stability and morality: An empirical study. Indian Journal of Psychological Issues. 